\section{Docomomo Internacional reconoce la antigua Jefatura Superior de Policía de Sevilla como patrimonio contemporáneo}

Dentro de la labor de registro que realiza la organización Docomomo Internacional, en el VII Congreso de Docomomo Ibérico se decidió la incorporación a su lista, entre otros inmuebles, de la antigua Jefatura Superior de Policía de Sevilla, un ejemplo notable de modernidad que plantea la dicotomía entre reconocimiento internacional y preservación local: su inclusión a un registro de alcance global se produce al mismo tiempo que se desarrolla un proceso de deterioro, expolio y abandono que queda oculto ante nuestros ojos con la cubrición de una Iona que abarca todo el edificio.

Como muestra del creciente interés que suscita el patrimonio arquitectónico del pasado siglo, valga comprobar cómo la organización Docomomo Internacional ha pasado en poco más de veinte años desde la modestia de los despachos de los profesores Henket y De Jonge en la Universidad de Delft a convertirse en una vasta estructura con sede en Barcelona, presidida por la profesora Ana Tostões, con representación en 53 países de África, América, Asia, Europa y Oceania, y más de 2.300 miembros.

Dentro de las actividades que organiza Docomomo Internacional, el proceso de registro reviste una especial complejidad, debido a la necesidad de contar con una selección ponderada de los edificios que lo compongan, que realiza anualmente su Comité de Registros (ISC/R), que encabeza el prestigioso historiador Panayotis Tournikoitis Para ello, desde 2003 este Comité estudia las aportaciones que anualmente remiten cada uno de los capitulos nacionales de la organización, y que con una orientación temática, buscan la mayor representatividad posible de la selección. Tras las lecturas realizadas sobre la Casa Moderna (2005), la Educación (2007), y la Industria (2008), entre otras, se consiguió ampliar este registro internacional, integrando obras tan significativas como la Casa y taller de Luis Barragán en México DF, el Illinois
Institute of Technology de Mies van der Rohe en Chicago, o la Fábrica Lingotto de Giacomo Matté Trucco en Turín.

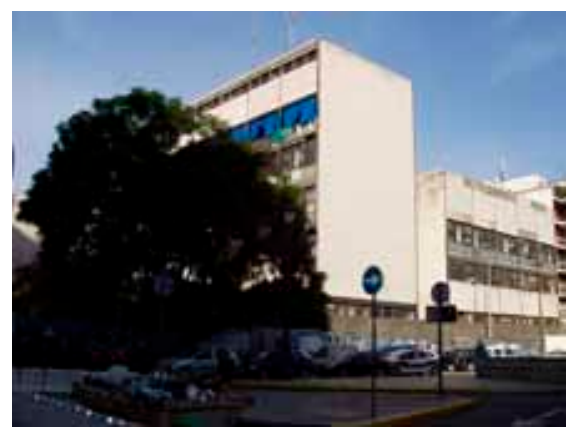

Imagen de la fachada de la antigua Jefatura Superior de Policía antes de su cubrición. Foto: Ignacio Capilla Roncero

Continuando esta apuesta por la ampliación del conocimiento, el Comité de registros orientó la selección del año 2009 hacia la temática de "El poder y el Movimiento Moderno" y en su reunión celebrada con motivo del VII Congreso Docomomo Ibérico, celebrado en Oviedo el pasado mes de abril, decidió la incorporación al registro de los siguientes edificios propuestos por Docomomo Ibérico: el Edificio del Cabildo Insular de Las Palmas en Gran Canaria (Miguel Martín Fernández de la Torre, 1929-1942), el Instituto Nacional de Estadística en Lisboa (Pardal Monteiro, 1931-1935), el Edificio de Hacienda en San Sebastián (Alejandro de La Sota, Manuel Sierra y José Maria Yturriaga, 1955-1965), la Delegación de Hacien- da en Oviedo (Ignacio Álvarez Castelao, 1958-1960), la Confederación Hidrográfica del Júcar en Valencia (Miguel Colomina Barberá, 1962-1968), y la Jefatura Superior de Policia en Sevilla (Ramón Montserrat Ballesté, 1962).

La incorporación del edificio de la antigua Jefatura Superior de Policía en Sevilla supone, por tanto, la validación internacional del reconocimiento a los valores patrimoniales de este edificio, tras su inclusión en trabajos y estudios especializados como el MoMo Andalucía (1999), el Registro Andaluz de Arquitectura Contemporánea (2008) y el Registro Docomomo Ibérico de los Equipamientos (2009): su imagen abstracta hacia la plaza de la Concordia, de grandes paños de revestimiento de piedra caliza combinados con carpinterias de perfiles de acero; la trasparencia del muro cortina, la amabilidad del acceso y el patio de las dependencias de atención al público, resultaban todo un manifiesto de modernidad, con claras resonancias a la obra de Alejandro de la Sota en el Gobierno Civil de Tarragona.

Sin embargo, es necesario recordar que este reconocimiento internacional al patrimonio histórico andaluz se realiza en condiciones de absoluta precariedad: Ios valores arquitectónicos, urbanos, sociales e históricos que ha apreciado el Comité hoy dia permanecen ocultos bajo una inmensa lona que tapa además la vergüenza de su abandono, expolio y vandalización. Ante esta cruda realidad, no podemos dejar de preguntarnos si en lugar de las poesias y las fotografías que reproduce dicha lona, no debería figurar la leyenda triste con la que Alvar Aalto bautizó su barco de Muuratsalo: Nemo propheta in patria, nadie es profeta en su tierra. Esperemos que las voces que llegan de fuera contribuyan a invertir esta lamentable situación.

Plácido González Martínez

Centro de Documentación y Estudios del IAPH 